\section{INFLUENCE OF NUTRITIONAL STATUS AT 36 WEEKS POSTMENSTRUAL AGE ON BODY COMPOSITION OF VLBW INFANTS ON THE FIRST TWO YEARS}

M. Sáenz de Pipaón Marcos ${ }^{1}$, I. Dorronsoro', B. San José ${ }^{2}$, S. Salas ${ }^{1}$, M. Martínez Biarge ${ }^{1}$, A.C. Hernández ${ }^{3}$, G.Á. Martos ${ }^{4}$, J. Argente ${ }^{4}$, J. Coya ${ }^{3}$, J. Quero ${ }^{1}$

${ }^{1}$ Neonatology, University Hospital La Paz, ${ }^{2}$ Research Unit, La Paz University Hospital, ${ }^{3}$ Nuclear Medicine, University Hospital La Paz, ${ }^{4}$ Pediatric Endocrinology, Niño Jesús University Children Hospital, Madrid, Spain

Objective: Compare body composition in the first two years between undernourished Very Low Birth Weight Infants (UNVLBWI), adequately nourished (AN) VLBWI and term infants (T).

Methods: Cohort study of $95 \mathrm{VLBWI},<34$ weeks GA, classified at 36 weeks PMA as UN (36, BW z-score $<-2)$ or AN (59, BW z-score $>-2)$ and 35 T. Fat Mass (FM) and BMD measured by DXA and TBW estimated using BIA at 6, 12, 18 and 24 months. FM was normalized for height to give FMI and for weight to give \% FM.

Results: FM was not different between $A N$ and $T$ from 12 months on, while UN had lower FM than $T$ in every time point.

\begin{tabular}{|l|l|l|l|l|}
\hline Group & $6 \mathrm{~m}$ & $12 \mathrm{~m}$ & $18 \mathrm{~m}$ & $24 \mathrm{~m}$ \\
\hline \multirow{2}{*}{ UN } & $0.26 \pm$ & $0.29^{ \pm}$ & $0.27^{ \pm}$ & $0.26 \pm$ \\
& $0.11^{\mathrm{a}}$ & $0.10^{\mathrm{a}}$ & $0.07^{\mathrm{a}}$ & $0.06^{\mathrm{a}}$ \\
\hline \multirow{2}{*}{$\mathrm{AN}$} & $0.37 \pm$ & $0.35 \pm$ & $0.35 \pm$ & $0.35^{ \pm}$ \\
& $0.12^{\mathrm{b}}$ & $0.11^{\mathrm{a}}$ & $0.11^{\mathrm{a}}$ & 0.08 \\
\hline \multirow{2}{*}{$\mathrm{T}$} & $0.46 \pm$ & $0.41 \pm$ & $0.37 \pm$ & $0.35 \pm$ \\
& $0.12^{\mathrm{a}, \mathrm{b}}$ & $0.13^{\mathrm{a}}$ & $0.1^{\mathrm{a}}$ & $0.09^{\mathrm{a}}$ \\
\hline
\end{tabular}

[FAT MASS INDEX]

FFM from TBW was significantly lower in preterm infants in all time points irrespective of nutritional status at 36 weeks PMA.

\begin{tabular}{|l|l|l|l|l|}
\hline Group & $6 \mathrm{~m}$ & $12 \mathrm{~m}$ & $18 \mathrm{~m}$ & $24 \mathrm{~m}$ \\
\hline \multirow{2}{*}{ UN } & $5065 \pm$ & $6567 \pm$ & $7582 \pm$ & $8383 \pm$ \\
& $593^{\mathrm{a}}$ & $899^{\mathrm{a}}$ & $758^{\mathrm{a}}$ & $862^{\mathrm{a}}$ \\
\hline \multirow{2}{*}{ AN } & $5811 \pm$ & $7032 \pm$ & $8230 \pm$ & $9183 \pm$ \\
& $584^{\mathrm{a}}$ & $677^{\mathrm{a}, \mathrm{b}}$ & $823^{\mathrm{a}, \mathrm{b}}$ & $930^{\mathrm{a}, \mathrm{b}}$ \\
\hline \multirow{2}{*}{ T } & $6197 \pm$ & $7771 \pm$ & $9031 \pm$ & $10039 \pm$ \\
& $621^{\mathrm{a}}$ & $794^{\mathrm{a}, \mathrm{b}}$ & $981^{\mathrm{a}, \mathrm{b}}$ & $1057^{\mathrm{a}, \mathrm{b}}$ \\
\hline
\end{tabular}

[FFM from TBW $(g)]$
Conclusion: Undernutrition at 36 weeks PMA but not prematurity is associated with lower \%FM and FMI at 12 and 24 months CA. FFM was higher in term than in preterm irrespective of nutritional status at discharge.

399

\section{ADRENAL INSUFFICIENCY DURING PHYSIOLOGICAL STRESS IN CHILDREN AFTER KIDNEY OR LIVER TRANSPLANTATION}

\author{
E. Bilavsky ${ }^{1}$, A. Dagan ${ }^{1}$, H.Y. Bilavsky ${ }^{1}$,
}

M. Davidovits ${ }^{1}$, R. Shapiro ${ }^{1}$, N. Weintrob ${ }^{2}$, J. Amir ${ }^{1}$, Y. Avitzur ${ }^{1}$

${ }^{1}$ Schneider Medical Center, Petah-Tikva, ${ }^{2}$ Dana Children's Hospital, Tel-Aviv, Israel

Objective: To assess the prevalence and risk factors of adrenal insufficiency ( $\mathrm{Al}$ ) in children after kidney or liver transplantation, hospitalized for a physiological stress episode, and to identify patients that might be at risk of adrenal crises by clinical and laboratory parameters at admission.

Patients and methods: Adrenal function was prospectively evaluated by standard (250 $\mu \mathrm{g})$ adrenocorticotropin test in 48 kidney or liver transplant pediatric recipients admitted for a physiological stress episode. Data on cumulative steroid treatment and clinical and laboratory findings were collected.

Results: Thirty-two patients were receiving longterm corticosteroids treatment and 16 were not. Al was diagnosed in 11 patients: $10(31.3 \%)$ on long-term treatment and in one $(6.25 \%)$ untreated. The only risk factor for Al was a cumulative dose of corticosteroids of $>0.15 \mathrm{mg} / \mathrm{kg} / \mathrm{d}$ in the last 6 months ( $p=0.02$, odds ratio of $6.67(95 \% \mathrm{Cl}$ : $0.97-$ 45.79)). There was no correlation between clinical or laboratory signs of adrenal crisis on admission and the presence of Al. None of the patients with Al who didn't receive stress dose $(n=8)$ developed adrenal crisis.

Conclusion: $\mathrm{Al}$ is present in about third of children receiving prolonged corticosteroid treatment after kidney or liver transplantation. Clinical parameters on admission can not reliably identify patients with Al. Universal administration of a stress dose during physiological stress is not required, and careful selection of patients who do require steroid stress dose is recommended. 